process, production and elementary occupations. (Abstract P4 Table $1)$. The reported prevalence of doctor-diagnosed respiratory disease was low $(15 \%)$, in particular smoking related lung disease (COPD, $5 \%$ ). An increased prevalence of impaired work performance was seen in breathless individuals with co-existent respiratory, cardiovascular or musculoskeletal disease with highest rates in those with declared lung disease. Dyspnoea, in many cases probably the result of COPD, is strongly and independently associated with suboptimal performance at work in later life. Strategies to better accommodate employees with breathlessness will be needed if, as planned, the age of the UK workforce does increase.

\section{P5 AIRWAY RESPONSIVENESS MEASUREMENTS IN ASTHMATIC RECRUITS TO EMERGENCY SERVICES}

doi:10.1136/thx.2010.150961.5

S Wiscombe, V Jeebun, SC Stenton. Royal Victoria Infirmary, Newcastle Upon Tyne, UK

Asthmatics undertaking emergency service work are thought to be at increased risk of severe bronchoconstriction with sudden exertion or exposure to irritants such as fire smoke, pepper spray or CS gas. The risks are poorly quantified and there are no clear guidelines to assist employers. We investigated the value of airway responsiveness measurements in 40 applicants to the police service who were thought to have asthma at a pre-employment examination. Their mean age was 25 years (SD 6 years); 22 (55\%) were male. Only 15 (37\%) reported active symptoms (wheeze, breathlessness or cough). Their median FEV1 was $106 \%$ of predicted (range $77-125 \%$ ) and only 3 demonstrated airflow obstruction. Airway responsiveness was measured as $\mathrm{PD}_{20} . \mathrm{FEV}_{1}$ to methacholine using the Newcastle dosimeter technique ${ }^{1}$ $16(40 \%)$ had measurements in the 'definite' asthma range, that is, $\mathrm{PD}_{20} . \mathrm{FEV}_{1}<200 \mu \mathrm{g} ; 6$ in the "equivocal" range $\mathrm{PD}_{20}$. $\mathrm{FEV}_{1}<200-1000 \mu \mathrm{g}$; and 18 in the 'normal' range $\mathrm{PD}_{20} . \mathrm{FEV}_{1}>1000$ $\mu \mathrm{g}$. There was a clear relationship between pre-employment FEV1 and PD20 within the definite asthma group $\left(\mathrm{F}_{(1,14)}=9.15 ; \mathrm{p}<0.001\right)$ but there were no significant associations between PD20 category and symptoms, medication use or lung function. We conclude that airway responsiveness measurements are practical in this setting and identify more than $50 \%$ of asthmatics as probably at low risk of marked bronchoconstriction. Further follow-up of the cohort will be necessary to more precisely determine the risks (Abstract P5 Table 1).

\section{Abstract P5 Table 1}

\begin{tabular}{lrlrl}
\hline & n & Current symptoms & Preventer inhaler & Median FEV1 \\
\hline Definite asthma & 16 & $8(50 \%)$ & $12(75 \%)$ & $106 \%$ \\
Equivocal asthma & 6 & $1(17 \%)$ & $5(83 \%)$ & $109 \%$ \\
Normal & 18 & $6(33 \%)$ & $10(55 \%)$ & $107 \%$
\end{tabular}

\section{REFERENCE}

1. Stenton SC, et al. Occup Med 1993;43:203-6.

\section{P6 WORK-RELATED RESPIRATORY SYMPTOMS IN THE UK; DO PRIMARY CARE PHYSICIANS MISS DIAGNOSTIC OPPORTUNITIES IN OCCUPATIONAL ASTHMA?}

doi:10.1136/thx.2010.150961.6

${ }^{1} \mathrm{~J}$ Hoyle, ${ }^{1} \mathrm{~L}$ Hussey, ${ }^{1} \mathrm{R}$ Barraclough, ${ }^{2} \mathrm{R}$ Agius. ${ }^{1}$ North Manchester General Hospital, Manchester, UK; ${ }^{2}$ Centre for Occupational \& Environmental Health, The University of Manchester, Manchester, UK

Introduction and objectives Occupational lung disease is prevalent and costly. Population-based studies show that up to 20 cases of occupa- tional lung disease per 100000 workers per year should be identified. ${ }^{1}$ The Health and Safety Executive estimates the cost of occupational asthma to our society to be over $£ 1.1$ billion for each 10 year period. ${ }^{2}$ The prognosis of these individuals is better if they are removed from exposure quickly; however, this policy leads to unnecessary job loss in cases where the diagnosis is wrong. ${ }^{3}$ Little is known about the number of workers who present to primary care with work-related symptoms, or what proportion of these are referred for hospital specialist advice once a work-related element has been identified.

Methods The Health \& Occupation Reporting network in General Practice (THOR-GP) at the University of Manchester, collects workrelated ill-health data from between 250 and 300 GPs trained to diploma level in occupational medicine. Cases of undiagnosed respiratory disease, reported as unspecified work-related respiratory symptoms between 2006 and 2009 were retrospectively identified. The cases were subdivided into exposure (if known) and categorised as referred if sent to a hospital specialist for further investigation. Results In 2006-2009 GPs reported 4902 cases of work-related illhealth, of which 115 (2\%) were reports of respiratory disease. 27 cases of non-specified work-related respiratory illness were identified. Only $26 \%(7 / 27)$ were referred for a specialist opinion despite uncertainty of diagnosis. Of those not referred, the majority $(17 / 20$ were exposed to known asthmagens as illustrated in Abstract P6 Figure 1 (consensus view after exposure review from three occupational/respiratory physicians)

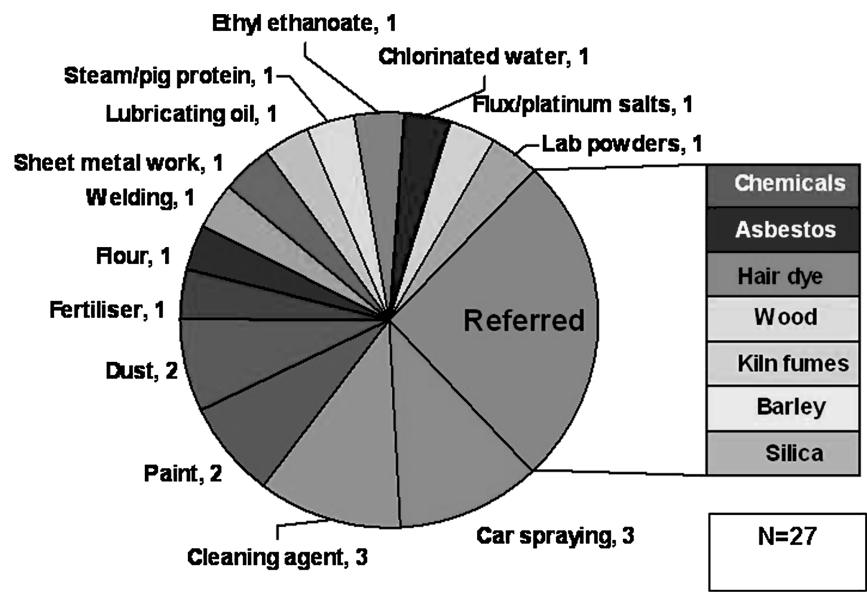

Abstract P6 Figure 1 Agents attributed to cases reported with respiratory symptoms referred to hospital specialists.

Conclusions More than three quarters of the cases with undiagnosed work-related symptoms identified in primary care were not referred to secondary care for diagnostic clarification. $85 \%$ of these cases were exposed to known asthmagens. The lack of diagnosis and/or specialist assessment in these cases may have significant impact on disease prognosis, disability and socio-economic cost to society.

\section{P7 OCCUPATIONAL EOSINOPHILIC CONSTRICTIVE BRONCHIOLITIS WITH ASTHMA IN A FOAM CUTTER CAUSED BY SOYA BEAN PRODUCTS}

doi:10.1136/thx.2010.150961.7

${ }^{1} \mathrm{~J}$ Hoyle, ${ }^{1} \mathrm{~K}$ Ballance, ${ }^{2} \mathrm{H}$ Francis, ${ }^{2} \mathrm{CAC}$ Pickering, ${ }^{2} \mathrm{RMc}$ Niven. ${ }^{1}$ North Manchester General Hospital, Manchester, UK; ${ }^{2}$ North West Lung Centre, Wythenshawe Hospital, Manchester, UK

Introduction and background Soya bean dust is a recognised cause of asthma. More recently Soya bean has bean used in the 
manufacture of foam. The main market for this 'environmentally friendly foam' is for cot mattresses. We describe a case of occupational asthma with eosinophilic constrictive bronchioloitis caused by cutting foam manufactured using Soya bean. This is the first case in world literature to the authors' knowledge where Soya bean induced respiratory allergy has been described in this way.

Case description 26-year male smoker presents with a 3-month history of fatigue, $10 \mathrm{~kg}$ weight loss, cough and work related breathlessness. Soya-based foam had been introduced into the work place 6 months prior to presentation, which the subject cut with a band knife. No respiratory protection or ventilation was used. No previous allergies or asthma were known. Throat itch preceded symptom onset. Other workers complained of conjunctivitis. At presentation the subject was apyrexial, oxygen sats $88 \%$ air, CRP 0.7, peripheral eosinophils 1.6 (14\%), WBC normal and FEV1 34\% predicted. Vasculitis and HIV screening negative. HRCT confirmed constrictive bronchiolitis, which resolved after a course of oral steroids. Lung function returned to normal. The subject was re-introduced to work where a marked drop in FEV1 was documented (Abstract P7 Figure 1). Bronchoscopy showed mucus plugging with eosinophilic casts. Peripheral eosinophilia increased with general fatigue. Total IgE remained normal, IgE for Aspergillus fumigatus $<0.4$. IgE for soya was 0.4 , but slightly elevated for other cross reactants. Skin tests for Soya bean and husk were positive. The worker was redeployed away from the foam cutting area but still had occasional exposure and peak flow variability compatible with occupational asthma, with increased non-specific bronchial hyper-reactivity on histamine challenge. Lung function, eosinophil count and bronchial reactivity stabilised following removal of the foam from the factory and home.

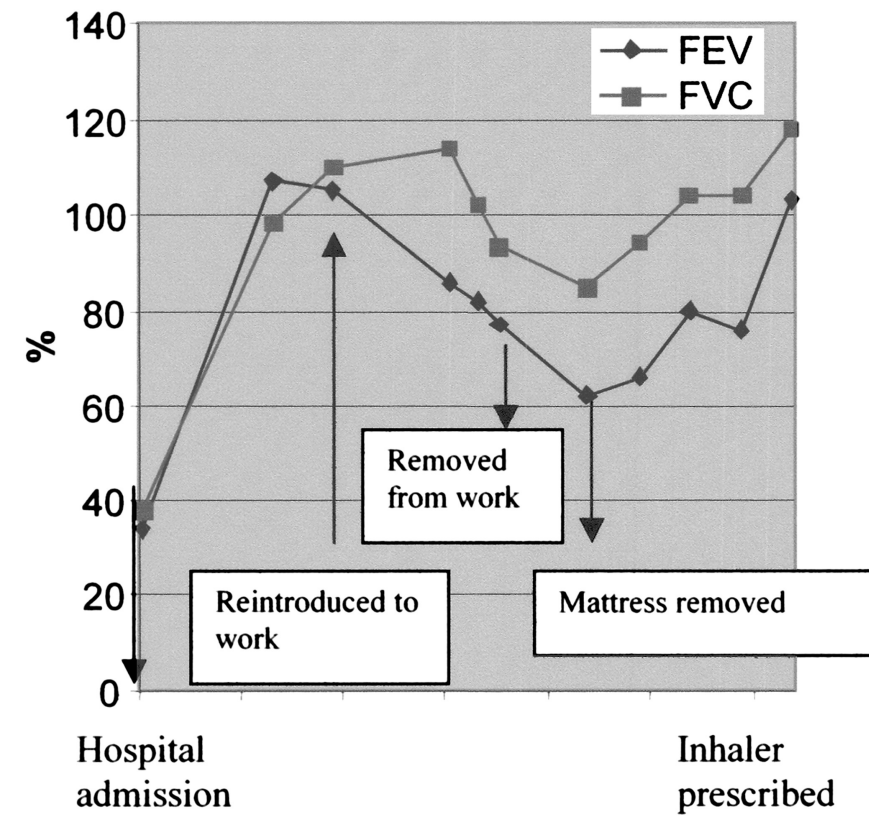

Abstract P7 Figure 1

Conclusion Eosinophilic airway plugging, with severe air trapping, reversible airflow obstruction and peripheral eosinophilia resolved after removing Soya bean based foam products from the work area and home. Skin prick tests confirm Soya bean allergy. The syndrome described has not been reported previously and may have implications for the foam manufacturing industry. P8
TONIQUE OUTBREAK OF OCCUPATIONAL ASTHMA IN
TOLMAKERS CAUSED BY CHROME

doi:10.1136/thx.2010.150961.8

GI Walters, VC Moore, AD Vellore, AS Robertson, PS Burge. Birmingham Heartlands Occupational Lung Disease Unit, Birmingham, UK

Introduction We describe a unique outbreak of occupational asthma in toolmakers due to chrome. We investigated four employees of a medium-sized manufacturer of precision jet-engine parts for workrelated asthma at our city hospital Occupational Lung Disease Unit. Case Series The four patients were aged between 35 and 56 and three of them had never smoked. They presented with new onset asthma and rhinitis symptoms that were subsequently diagnosed as occupational based on 2-h peak expiratory flow measurements (OASYS-2 scores range: 3.25-4.00). Two of the patients had impaired lung function at diagnosis. One case showed a dual asthmatic response and two cases showed early asthmatic reactions to potassium dichromate $2 \mathrm{mg} / \mathrm{ml}$ on specific inhalation challenges. The fourth case had a small late reaction only to cobalt chloride $10 \mathrm{mg} / \mathrm{ml}$. (Abstract P8 Figure 1).

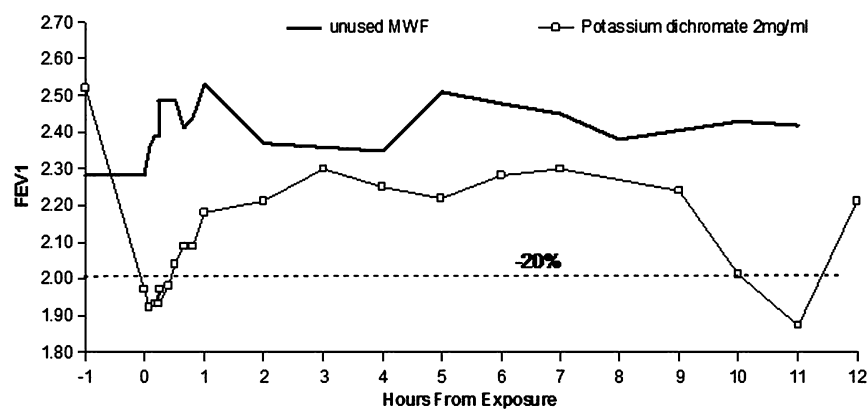

Abstract P8 Figure 1 Specific inhaled challenge test from case 1, showing dual asthmatic responses to inhaled potassium dichromate ( $2 \mathrm{mg} / \mathrm{ml}$ ). There was no response to either used MWF or cobalt chloride (not shown on the plot).

Discussion All workers were sensitised within the preceding 5 years, before which the metalworking fluid brand and composition was changed. The latency onset of symptoms ranged from 6 to 24 months. This suggests leaching of the chrome and cobalt into this particular oil. Skin prick responsiveness and exhaled nitric oxide were not good predictors of airways response. Occupational asthma caused by chrome sensitisation is rare but has been described in electroplaters (1), steel welders (2) and construction workers (3); this is the first outbreak in toolmakers.

\section{REFERENCES}

1. Bright P, Burge PS, O'Hickey S, et al. Occupational asthma due to chrome and nickel electroplating. Thorax 1997;52:28-32.

2. Keskinen $\mathbf{H}$, Kalliomä Ki PL, Alanko K. Occupational asthma due to stainless steel welding fumes. Clin Allergy 1980;10:151-9.

3. Cockcroft DW, Killian DN, Mellon JJA, et al. Bronchial reactivity to inhaled histamine: a method and clinical survey. Clin Allergy 1977;7:235-43.

\section{\begin{tabular}{|l|l}
\hline P9 & THE EVALUATION OF AN IMPROVED METHOD OF
\end{tabular} OCCUPATIONAL ASTHMA DIAGNOSIS FROM TIMEPOINT ANALYSIS OF SERIAL PEF RECORDS}

doi:10.1136/thx.2010.150961.9

${ }^{1}$ CBSG Burge, ${ }^{1} \mathrm{VC}$ Moore, ${ }^{1}$ AS Robertson, ${ }^{2} \mathrm{CFA}$ Pantin, ${ }^{1} \mathrm{PS}$ Burge. ${ }^{1}$ Birmingham Heartlads Hospital, Birmingham, UK; ${ }^{2}$ University Hospital of North Staffordshire, Stoke on Trent, UK

Background The diagnosis of occupational asthma requires objective confirmation. Analysis of serial measurements of Peak Expiratory 